\title{
SCIDOC
}

International Journal of Dentistry and Oral Science (IJDOS)

ISSN: 2377-8075

\section{Fracture Resistance Of Molars Restored With Endocrowns Made Of Lithium Disilicate Glass-Ceramic And Polyetherethereetone PEEK: An In-Vitro Study}

\author{
Research Article
}

Yasmeen Ghalawingy $^{1}$, Issam Jamous ${ }^{2}$, Zuhair Al-Nerabieah ${ }^{3 *}$

${ }^{1}$ MSc, Department of Fixed Prosthodontics, Faculty of Dentistry, Damascus University, Syria.

${ }^{2}$ PhD, Lecturer, Department of Fixed Prosthodontics, Faculty of Dentistry, Damascus University, Syria

3: Paediatric dentistry department, Dental collage, Damascus University, Al-Mazzeh St. Damascus, PO Box 30621, Syria

\section{Abstract}

Objective: The aim of this study was to evaluate the fracture resistance and failure modes of endodontically treated molars restored with endocrowns made of polyetheretherketone (PEEK) and lithium disilicate glass-ceramic (LDS).

Methods: Thirty-six extracted mandibular molars were randomly divided into three groups $(n=12)$. Teeth in group1 (intact) were left without any treatment. Remaining teeth were sectioned parallel and $2 \mathrm{~mm}$ above CEJ, undergone to standardized preparation and endodontic treatment, then composite was applied on pulp chamber floor to ensure a depth of $3 \mathrm{~mm}$ for all cavities. Endocrown restorations made of LDS were used for group2 (e-max), while PEEK veneered with $1 \mathrm{~mm}$ layer of composite was used to fabricate endocrowns for group3 (PEEK).

Following adhesive cementation, a compressive axial load was applied until failure using a universal testing machine. Fracture loads and Failure modes were recorded. Statistically analysis was performed using one-way analysis of variance.

Results: Mean fracture loads of all groups were higher than normal occlusal forces. Mean fracture strength of group (e-max) was $(4842 \mathrm{~N})$ and showed significantly higher value than that of other two groups $(\mathrm{p}<0.05)$, whilst mean fracture loads of groups (intact) and (PEEK) did not show statistically differences (2708 and $2559 \mathrm{~N}$ respectively). All specimens of group (PEEK) exhibited repairable fractures. In contrast, all samples of group (e-max) exhibited irreparable fractures, while failure modes of group (intact) ranged between repairable and irreparable.

Conclusion: Endocrowns made of PEEK can be used to restore endodontically treated molars as they provide a conservative treatment modality with the ability to modify and repair if necessary.

Keywords: Endocrown; Fracture Resistance; Lithium Disilicate Glass-Ceramic; Peek.

\section{Introduction}

Despite all developments in dentistry and its materials, restoring of endodontically treated teeth with excessive coronal destruction is still a challenge for clinicians[1]. Many methods have been introduced to restore damaged teeth including direct restorations, indirect ones such as inlays, onlays, and full coverage crowns supported by cast metal posts and cores, fiber posts with composite resin cores or other techniques[2-5].

The amount of coronal structure remains, as well as, the type of tooth whether it is incisor, canine, premolar, or molar affect choosing the appropriate method to restore these dilapidated teeth[6]. Using any type of intraradicular posts to support a crown requires much more removal of sound radicular dentine, therefore, the tooth will be weaker[7] and the probability of causing a root perforation and thinning of the root canal walls due to over preparation might increase[8].

Nowadays, the development of adhesive dentistry has reduced the need of posts and cores to restore endodontically treated posterior teeth with extensive coronal tissue loss[9]. Pissis introduced the "mono-block porcelain technic" which is a full ceramic restoration depends on micromechanical retention by adhesive cementation and macromechanical retention by pulp chamber walls[10].

In 1999 Bindl and Mormann[11] proposed the term "Endocrown" to describe such restoration that assembles the intraradic-

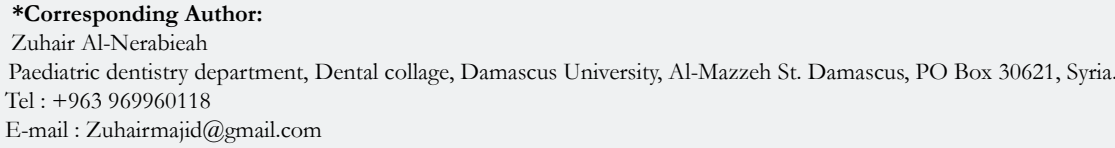

Citation: Yasmeen Ghalawingy, Issam Jamous, Zuhair Al-Nerabieah. Fracture Resistance Of Molars Restored Withendocrowns Made Of Lithium Disilicate Glass-Ceramic And Polyetherethereetone PEEK: An In-Vitro Study . Int J Dentistry Oral Sci. 2021;8(7):3311-3317. doi: http://dx.doi.org/10.19070/2377-8075-21000675

Copyright: Zuhair Al-Nerabieaz ${ }^{\mathcal{O}}$ 2021. This is an open-access article distributed under the terms of the Creative Commons Attribution License, which permits unrestricted use, distribution and reproduction in any medium, provided the original author and source are credited. 
ular post, the core and the crown in one component and can be bonded to a depulped posterior tooth.

According to literature, endocrown has exhibited excellent results regarding the clinical performance[12], in addition it presents excellent mechanical and aesthetic properties[5,9,13,14]. Moreover, endocrown does not require additional removal of intact radicular dentine, this specific property is important when the tooth has short, thin, curved roots[4]. As well as it can be placed in cases in which there is no sufficient interocclusal space to restore with crown supported by post and core $[9,15]$. Compared with conventional crowns with a cast post and core or a fiber post and resin core, many studies have found endocrowns were more resistant to fracture $[4,15,16]$.

Acid-etchable ceramics have been considered the material of choice for the fabrication of endocrown because they provide aesthetics, adequate mechanical properties to withstand occlusal forces and adequate bond strength to tooth structure[17,18]. Recently, a high-performance polymer, polyetheretherketone (PEEK) has been introduced in dentistry.

PEEK is a semi-crystalline linear polycyclic aromatic, characterizes by excellent physical, mechanical and chemical properties. It has a low elasticity modulus (3-4 GPa) close to that of human bone, enamel and dentine[19-22]. PEEK is biocompatible, nonallergic and has low plaque affinity[21].

Modified PEEK containing 20\% ceramic fillers known as BioHPP® (Bredent GmbH Senden, Germany). It distinguished by excellent stability, great optimal polishable properties, and aesthetic white shade of BioHPP $®$ helps to produce high-quality prosthetic restorations[23]. Literature has documented multiple uses of PEEK in dentistry. PEEK intraosseous implants and implant abutments showed very promising results[19,22-25]. PEEK proved eligibility to be a substitute for metal framework in full crowns[26], fixed[19,22,25,27] and removable [28,29] partial dentures. Unfortunately, due to PEEK's grayish-brown color, it is not suitable for monolithic restorations of anterior teeth[30], thus, more aesthetic material such as composite should be used for coating to get an aesthetic result.

Numerous studies have been conducted to examine the bond strength of the adhesives/composite resin to PEEK after using different surface conditioning methods[30-33], they could reach bond strength up to $21.4 \mathrm{MPa}$. Regarding the literature, a large number of in-vivo[9,11,12,14,34,35] and in-vitro studies[12,36-41] evaluated the clinical performance and mechanical behavior of endocrown using approximately all types of dental ceramics and composites. However, only one case report[42] and two in-vitro studies $[43,44]$ experimentedmodern polyetheretherketoneas a material for endocrown restoration.

Therefore, the purpose of this in-vitro study was to compare the fracture resistance and failure modes of endodontically treated molars restored with endocrown made of PEEK and lithium disilicate glass-ceramic (LDS).

The null hypothesis of this study was that the use of different restoration materials would not affect fracture resistance and failure mode of endodontically treated molars.

\section{Materials And Methods}

Thirty-six sound extracted mandibular third molars with nearly similar size (mesio-distal: $9.12 \pm 0.43 \mathrm{~mm}$; bucco-lingual: $8.7 \pm$ $0.44 \mathrm{~mm}$ ), free of carious lesions, with complete root morphology, were collected for this study. Specimens were randomly divided into three groups $(\mathrm{n}=12)$ according to materials used.

Teeth in group 1 (intact) were left without any treatment and they were considered as the control negative group. Samples in group 2 (e-max) were restored withendocrown made of lithium disilicate glass ceramic, and teeth in group 3 were restored withendocrown made of a core of polyetheretherketone (PEEK) covered with composite resin.

Using metallic molds each tooth was embedded vertically in autopolymerizing acrylic resin, $2 \mathrm{~mm}$ below cemento-enamel junction (CEJ). In the endocrown groups, reducing occlusal surface to form a flat butt-joint parallel and $2 \mathrm{~mm}$ above cemento-enamel junction was performed using cylindrical diamond bur $2 \mathrm{~mm}$ in diameter.

Butt joint was smoothen using diamond wheel bur. Endodontic access cavities were prepared, then; a standardized endodontic treatment was performed for all specimens. Eugenol free temporary filler (MD-Temp, Meta Biomed, Korea) was applied to ensure setting of canal's filler.

One week later, residual gutta-percha and sealer were removed using a round carbide bur. To seal canals' orifices and uniform the depth of intra-coronal cavity $(3 \mathrm{~mm}$ from the surface of the butt-joint), composite resin restorations (Tetric N-Ceram, Ivoclar, Vivadent, Schaan,Liechtenstein)were applied using incremental technique, and each layer was light-cured for 40 seconds. A pencil and pre-cut plastic sheet were used to colour dentine outer borders of the cavity to ensure all cavities would measure $4 \mathrm{mmbucco}$-lingualy and $5 \mathrm{~mm}$ mesio-distaly after preparation. Standardized pulpal walls preparation was performed with occlusal convergence of $60-10 \mathrm{o}$ angled using a flat-end tapered diamond bur holding parallel to the long axis of the tooth and following the pulp chamber's colored border. Internal line angles were rounded, and using graded periodontal probe, all measurements were verified.

Putty-wash technique impressions were performed using condensation silicon (Zetaplus and Oranwash L, Zhermack, Rovugo, Italy).Master casts were scanned with a CAD-CAM scanner (AcuBlu, UP3D, Shenzhen, China) and data were transferred to CAD software (exocad, Dental DB, 2018), which was used to make similar full anatomy design of first mandibular molar for all restorations on the virtual models (Figure 1, A). $5 \mathrm{~mm}$ was the height of designed endocrown measured from the butt-joint to the tips of buccal cusps. Machinable wax was used to fabricate all restorations using a 5-axis milling machine (DWX-52D,DGSHAPE, Roland DG, Hamamatsu, Japan).

For group 2 (e-max), wax sprues were attached to wax endocrowns before investing in investment material, then,IPS e.max Press (Ivoclar, Vivadent, Schaan,Liechtenstein) was used to fabricate ceramic endocrowns according to manufacturer recommendations. Finally, restorations were separated and glazed using IPS Ivocolor (Ivoclar, Vivadent, Schaan,Liechtenstein). For group3 
(PEEK), each wax pattern was set on its corresponding cast, then, a vacuum device and acetate plate were used to make a mold of endocrowns. Virtual models of CAD software were used again to fabricate another design for endocrown's PEEK cores (Figure 1, B). Using shrinkage technique, the new design was $1 \mathrm{~mm}$ smaller than the former in all its dimensions. After that, PEEK cores (DD peek MED, Dental Direkt materials, GmbH, Germany) were milled using the 5 -axis milling machine.

Outer surfaces of PEEK cores were sand-blasted using $50 \mu \mathrm{m}$ Aluminum Oxide (AL2O3) particles, at a pressure of 2.5 bar, for10 seconds. After cleaning by distilled water, a layer of adhesive agent (visio-link, Bredent, Senden, Germany) was applied on the outer surfaces using a micro-brush and light-cured for $90 \mathrm{sec}$ according to manufacturer recommendations.

PEEK cores were set on theirs corresponding casts and using incremental technique, cores were covered with condensing $1 \mathrm{~mm}$ thickness micro-hybrid composite resin (Tetric N-Ceram, Ivoclar, Vivadent, Schaan,Liechtenstein) with the help of previously made acetate molds. Excessive composite was removed and endocrowns were finished and polished.

To improve composite's mechanical properties, PEEK endocrowns were additionally photo-polymerized using laboratory LED light-curing unit with temperature of $60 \mathrm{o} C$ for 10 minutes. Before cementation, all restorations were fitted on their corresponding teeth.

The intaglio surfaces of e-max endocrowns were etched using hydrofluoric acid gel ( $9 \%$ porcelain etch, Ultra Dent, South Jordan, UT, USA) for 60 seconds, then, they were rinsed off with water spray for 20 seconds and air-dried until chalky appearance became obvious. A thin layer of silane coupling agent (Universal Silane, Ultra Dent Products, UT, USA) was applied using microbrush and left for 60 seconds to evaporate.

For PEEK endocrowns, sandblasting and adhesive agent were used to treat intaglio surfaces the same technique aforementioned. Recipient teeth were etched using selective etching technique by applying 37\% phosphoric acid (Eco-Etch, Etching Gel, Ivoclar, Vivadent, Schaan,Liechtenstein) for 30 seconds on the enamel tissue and for 15 seconds on the dentine tissue, rinsed off with water spray for 20 seconds and gently air-dried to avoid the collapse of dentine's collagen.

The bonding agent (Tetric N-Bond Universal, Ivoclar, Vivadent, Schaan,Liechtenstein) was applied on the prepared teeth, left for 20 seconds, air-blowed and light-cured for 10 seconds. Both types of restorations were lutted using a dual-cure resin cement (Variolink N, Base and Catalyst, Ivoclar, Vivadent, Schaan,Liechtenstein). Same amount of base and catalyst were mixed carefully and applied onto the intaglio surfaces of endocrowns. All restorations were seated accurately with light finger pressure on the corresponding prepared teeth, followed by brief light-curing for 3-5 seconds to remove the excess of luting cement, then each surface was photo-polymerized for 40 seconds.

After that, samples were kept in distilled water at room temperature for 72 hours. Universal testing machine (Testometric, Rochdale, England) with a $5.5-\mathrm{mm}$ diameter stainless steel semi-ball, at a cross-head speed of $0.5 \mathrm{~mm} / \mathrm{min}$, was used to perform the fracture test. Samples were vertically loaded on the center of the occlusal surface (axial loading). The maximum force of fracture was recorded in newton $(\mathrm{N})$, then, all specimens were visually examined and the failure modes were classified according to following table (Table 1).

\section{Statistical Analysis}

Statistical analysis of all obtained data was performed using SPSS software (version 25). Shaprio-Wilktest was used to test the normal distribution of fracture resistance outcomes. All results were normally distributed ( $\mathrm{p}>0.05)$. One-way ANOVA was used to compare mean fracture resistance between the three groups. Variables were expressed as the mean \pm standard deviation. GamesHowell post hoc test was used to compare significant differences between groups.Fisher's exact test was used to evaluate the fracture types.

Results were considered statistically significant when $\mathrm{p}$ value showed less than 0.05 for all tests.

\section{Results}

Mean fracture resistance (in Newton) for group (e-max) was (4842 $\mathrm{N}$ ), followed by $(2708 \mathrm{~N}$ ) for group (intact), while group (PEEK) had the least mean fracture resistance $(2559 \mathrm{~N})$. The mean fracture strength of the groups with respective standard deviations, minimum and maximum values are seen in table 2 . According to results, group (e-max) showed significantly higher fracture strength than other two groups $(\mathrm{p}<0.05)$, while no significant differences were determined between (intact) and (PEEK) groups $(p>0.05)$. The results of the groups' failure modes are shown in table 3 . Regarding the mode of failure, results showed that all specimens of group (PEEK) exhibited repairable fractures (the fracture occurred in the interface between PEEK and composite in all sam-

FIGURE 1: Designing of the restorations. Designing a full anatomy of first mandibular molar for all wax endocrowns on the virtual models (A), Designing PEEK cores $1 \mathrm{~mm}$ smaller than the full anatomy design in all dimensions (B).

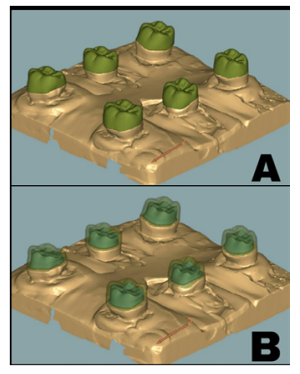


FIGURE 2: Failure modes. Repairable fracture of intact group (did not exceed CEJ) (A1), irreparable fracture of intact group (exceeded CEJ) (A2), irreparable fractures of e-max group (B1-B3), Repairable fractures of PEEK group (Limited in veneering composite) $(\mathrm{C} 1, \mathrm{C} 2)$.

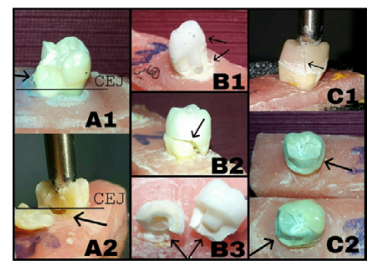

TABLE 1: Classification of failure modes.

\begin{tabular}{|c|c|c|c|}
\hline Type & Failure mode & Description & Prognosis \\
\hline I & Cohesive failure & Fracture of the restoration & Repairable \\
\hline II & $\begin{array}{c}\text { Fracture of the restoration/ } \\
\text { tooth complex above the (CEJ) }\end{array}$ & $\begin{array}{c}\text { Fracture of the restoration } \\
\text { and the tooth above the } \\
\text { CEJ }\end{array}$ & Repairable \\
\hline III & $\begin{array}{c}\text { Fracture of the restoration/ } \\
\text { tooth complex below the (CEJ) }\end{array}$ & $\begin{array}{c}\text { Fracture of the restoration } \\
\text { and the tooth below the } \\
\text { CEJ, which require tooth } \\
\text { extraction }\end{array}$ & Irrepairable \\
\hline
\end{tabular}

TABLE 2: Results of fracture strength

\begin{tabular}{|c|c|c|c|c|c|}
\hline Groups & Mean fracture resistance & SD & Median & Max & Min \\
\hline Intact & 2708 & 753 & 2777 & 3682 & 1488 \\
\hline E-max & 4842 & 1593 & 5331 & 7202 & 1518 \\
\hline PEEK & 2559 & 461 & 2523 & 3205 & 1859 \\
\hline
\end{tabular}

TABLE 3: Results of Failure modes

\begin{tabular}{|c|c|c|c|}
\hline Groups & $\mathbf{n}$ & $\begin{array}{c}\text { Failure mode } \\
\text { (Repairable) }\end{array}$ & $\begin{array}{c}\text { Failure mode } \\
\text { (Irreparable) }\end{array}$ \\
\hline Intact & 12 & $5(41.6 \%)$ & $7(58.3 \%)$ \\
\hline E-max & 12 & $0(0 \%)$ & $12(100 \%)$ \\
\hline PEEK & 12 & $12(100 \%)$ & $0(0 \%)$ \\
\hline
\end{tabular}

ples) as seen in figure 2, C1, C2. In contrast, all samples of group (e-max) exhibited irreparable fractures (the fracture involved both restoration and tooth and extended below CEJ) as seen in figure 2, B1-B3, while failure mode of group (intact) ranged between repairable ( 5 samples) and irreparable (7 samples) as seen in figure 2, A1 and A2respectively. Group (PEEK) showed significant difference compared to other two groups.

\section{Discussion}

With the development of adhesive dentistry, the need for using post and core has reduced[13]. Etchable ceramics such as those reinforced with lithium disilicate, associated with the adhesive systems and resin cements, has made it possible to restore posterior teeth, especially molars, without cores and intraradicular posts [9 ,45]. Furthermore, previous studies have favored the use of lithium disilicate for the fabrication of endocrowns[18,46,47].

In recent years, polyetheretherketone (PEEK) with its high physical, mechanical and chemical properties has been increasingly introduced to prosthetic dentistry[19,23]. Studies and clinical reports have demonstrated favorable performance of prosthesis made of PEEK[26-28]. However, there is no sufficient evidence that peek covered with composite resin can be used as an alternative material of endocrown restoration.

Thus, the purpose of this study was to compare the fracture resistance and failure modes of endodontically treated molars restored withendocrown made of peek and lithium disilicate glass-ceramic (LDS).In the current study, the use of natural molars might have increased the variability of the fracture load compared with artificial teeth. However, the use of natural teeth closely approximates clinical situation regarding tooth architecture and morphology.

To decrease these variables, a strict inclusion criteria was used including bucco-lingual and mesio-distal dimensions. Furthermore, a standardized endodontic treatment, preparation and restoration design was performed for all specimens.Many studies have evaluated the effect of intra-coronal depth of teeth restored with endocrowns on fracture resistance $[41,43,48]$. In this context, fracture resistance of depulped molars restored with ceramic endocrowns extend $1 \mathrm{~mm}, 3 \mathrm{~mm}$ and $5 \mathrm{~mm}$ inside the pulp chambers has been compared, authors concluded that greater extension of endocrowns inside the pulp chamber provided better mechanical 
performance[41]. Another study recommended that pulp chamber extension should not be less than $3 \mathrm{~mm}[17]$.Numerous studies have looked for the optimum method to obtain enough bond strength between PEEK and composite[31,49,50]. In this study, the choice of PEEK surface treatment was based on recommendations of most of related articles[32].

In the current study, mean fracture loads of all groups were higher than the reported physiologic occlusal forces which vary from 200 to $900 \mathrm{~N}$ [51]. According to results, the mean fracture resistance and failure modes of group 1 (intact) were comparable to those of a previous study that reported a mean fracture resistance of intact teeth of $(2596 \pm 459) \mathrm{N}$, and $80 \%$ of fractures were irreparable[39].Group 2 (e-max) showed the higher mean fracture resistance, which significantly different from that of two other groups.

The monolithic nature and large thickness of ceramic endocrown restoration could justify the high fracture strength in the currentstudy. Moreover, high mechanical performance of (LDS) due to presence of crystalline particles increases the fracture strength against loading[52]. These results are in accordance with previous studies that reported the superiority of reinforced glass ceramic endocrowns in terms of fracture resistanceover other materials $[38,39,44]$.

On the other hand, some studies reported that resin nano-ceramics (RNC)endocrowns showed the highest mean fracture load value over lithium disilicate ceramic, polymer infiltrated ceramics and zirconia-reinforced lithium silicate ceramics (ZLS) [53,54]. Industrial fabrication of these blocks under high temperature and high pressure has led to a high volume fraction filler and high conversion, thus significantly improving their mechanical properties $[55,56]$.

Unfortunately, failure modes of all specimens in group (e-max) were irreparable. This result can be explained by the fact that the development of fracture in tooth extended under endocrown increased bending of the endocrown material and, thus, accelerates its fracture. Hence, this process depends on the strength of the tooth (the base of the construction)[40]. A previous study also reported that the highest rate of irreparable fractures were occurred in (LDS) group in comparison with (ZLS), and (RNC) groups under axial and lateral forces[38].

They related these outcomes to the difference in modulus of elasticity between the materials. (LDS) is more rigid than the other two materials and has a high modulus of elasticity, which concentrates strain in weak area and results in irreparable fractures [57].

Same results were found when fracture modes of (LDS) and two types of composite endocrowns were compared[39].In the current study, group 3 (PEEK) showed relatively high mean fracture resistance which could be comparable to unrestored teeth. This result is not surprising regarding high mechanical performance, fracture resistance and stiffness of PEEK polymer. Additionally, PEEK has low elastic modulus (4 GPa) similar to human bone, enamel, and dentin, thus, it subside applied forces and distribute stresses by cushioning effect[26].

High bond strength between PEEK polymer and composite resin also play a role in enhancing fracture strength[23]. Findings of this study are ,somewhat, in agreement with another one which reported high fracture resistance $(3026 \pm 270 \mathrm{~N})$ of endodontic treated premolars restored withendocrown made of PEEK[43].

However, mean fracture load of PEEK group in mentioned study was significantly higher than that of e-max group. Oblique forces applied on restored premolars at $45 \mathrm{O}$ angle reduced the forces required to fracture e-max samples in comparison with axial forces applied on relatively larger molars in our study[38].

On the other hand, fracture modes of all PEEK specimens in our study and a recent one were repairable[44], compared to mixed fracture involving PEEK restoration and dentine in the previous study. This result can be justified by the presence of veneering composite resin in the recent two studies, which split away from underlying PEEK.

Fortunately, the mean fracture load required to separate composite layer was much higher than the reported maximum masticatory forces applied in molar region even in parafunction cases such as "bruxism", that can apply occlusal loads up to approximately $1000 \mathrm{~N}[58]$.

Clinically, beside stress absorption advantage of endocrown made of PEEK, the veneering composite makes it possible to repair fractured segment, if necessary, directly and intra-orally instead of replacing all the restoration. Furthermore, in some cases in which it is essential to modify the restoration such as raising the vertical dimensionor in the context of orthodontic treatment, veneering composite could be altered easily. Another advantage of PEEK is that it does not wear the opposing natural teeth[59]. However, PEEK can be significantly affected by aging other than (LDS) [44].

As with all in-vitro studies, this study has limitations. Although it is necessary to mimic the clinical situation in in-vitro tests, the periodontium around the roots was not simulated in the present study. During the fracture test, the movement of specimens according to the ligament simulation material could change the fracture resistanceresults and failure modes positively[60].However, teeth roots were embedded into acrylic resin, $2 \mathrm{~mm}$ below CEJ, to simulate the alveolar bone. In addition, thermo-mechanical cycling was not applied in all of the groups. Thus, the clinical relevancy of such aging methods has to be correlated with clinical studies in the future.

\section{Conclusion}

Within the limitations of the current study, it can be concluded that minimum fracture load of endocrowns made of lithium disilicste glass ceramic or PEEK veneered with composite resin, was much higher than the maximum masticatory forces.

Although (LDS)endocrowns showed higher fracture resistance than PEEK ones, they showed more irreparable failure rates.

Based on the results of the current study and in light of the available literature, endocrowns made of PEEK can be used to restore endodontically treated molars as they provide a conservative treatment modality with the ability to modify and repair if necessary. However, further investigations are required to confirm their long-term success in different clinical situations. 


\section{Acknowledgment}

Damascus University Funded this study

\section{References}

[1]. Ploumaki A, Bilkhair A, Tuna T, Stampf S, Strub JR. Success rates of prosthetic restorations on endodontically treated teeth; a systematic review after 6 years. J Oral Rehabil. 2013 Aug;40(8):618-30.Pubmed PMID: 23663088

[2]. Plotino G, Buono L, Grande NM, Lamorgese V, Somma F. Fracture resistance of endodontically treated molars restored with extensive composite resin restorations. J. Prosthet. Dent. 2008 Mar 1;99(3):225-32.

[3]. Cobankara FK, Unlu N, Cetin AR, Ozkan HB. The effect of different restoration techniques on the fracture resistance of endodontically-treated molars. Oper. Dent. 2008 Sep;33(5):526-33.

[4]. Biacchi GR, Basting RT. Comparison of fracture strength of endocrowns and glass fiber post-retained conventional crowns. Oper Dent. $2012 \mathrm{Mar}-$ Apr;37(2):130-6.Pubmed PMID: 21942234

[5]. Atash R, Arab M, Duterme H, Cetik S. Comparison of resistance to fracture between three types of permanent restorations subjected to shear force: An in vitro study. J Indian Prosthodont Soc. 2017 Jul-Sep;17(3):239-249.Pubmed PMID: 28936037.

[6]. Rosenstiel SF, Land MF, editors. Contemporary fixed prosthodontics-ebook. Elsevier Health Sciences; 2015 Jul 28.

[7]. Soares CJ, Santana FR, Silva NR, Preira JC, Pereira CA. Influence of the endodontic treatment on mechanical properties of root dentin. J. Endod. 2007 May 1;33(5):603-6.

[8]. Asmussen E, Peutzfeldt A, Sahafi A. Finite element analysis of stresses in endodontically treated, dowel-restored teeth. J Prosthet Dent. 2005 Oct;94(4):321-9.Pubmed PMID: 16198168.

[9]. Belleflamme MM, Geerts SO, Louwette MM, Grenade CF, Vanheusden AJ, Mainjot AK. No post-no core approach to restore severely damaged posterior teeth: An up to 10-year retrospective study of documented endocrown cases. J. Dent. 2017 Aug 1;63:1-7.

[10]. Pissis P. Fabrication of a metal-free ceramic restoration utilizing the monobloc technique. Pract Periodontics Aesthet Dent. 1995 Jun-Jul;7(5):83-94. Pubmed PMID: 7548896.

[11]. Bindl A, Mörmann WH. Clinical evaluation of adhesively placed Cerec endo-crowns after 2 years--preliminary results. J Adhes Dent. 1999 Autumn;1(3):255-65.Pubmed PMID: 11725673.

[12]. R. A. Al-Dabbagh. Survival and success of endocrowns: a systematic review and meta-analysis. J. Prosthet. Dent. 2020.

[13]. Sedrez-Porto JA, da Rosa WL, da Silva AF, Münchow EA, Pereira-Cenci T. Endocrown restorations: A systematic review and meta-analysis. J. Dent. 2016 Sep 1;52:8-14.

[14]. Dogui H, Abdelmalek F, Amor A, Douki N. Endocrown: An Alternative Approach for Restoring Endodontically Treated Molars with Large Coronal Destruction. Case Rep Dent. 2018 Aug 30;46:1-6.Pubmed PMID: 30228915.

[15]. Chang CY, Kuo JS, Lin YS, Chang YH. Fracture resistance and failure modes of CEREC endo-crowns and conventional post and core-supported CEREC crowns. J. Dent. Sci. 2009 Sep 1;4(3):110-7.

[16]. Dejak B, Młotkowski A. 3D-Finite element analysis of molars restored with endocrowns and posts during masticatory simulation. Dent Mater. 2013 Dec 1;29(12):e309-17.

[17]. Fages M, Bennasar B. The endocrown: a different type of all-ceramic reconstruction for molars. J Can Dent Assoc. 2013;79:d140.Pubmed PMID: 24309044 .

[18]. N. Govare and M. Contrepois.Endocrowns: A systematic review. J. Prosthet. Dent. 2019.

[19]. Tekin S, Cangül S, Adıgüzel Ö, Değer Y. Areas for use of PEEK material in dentistry. Int. Dent. Res. 2018 Aug 27;8(2):84-92.

[20]. Manolea HO, Obădan F, Popescu SM, Rîcă R, Mărăsescu P, Iliescu AA, et al. Current Options of Making Implant Supported Prosthetic Restorations to Mitigate the Impact of Occlusal Forces. Defect Diffus. Forum. 2017 ;376:66-77.

[21]. Skirbutis G, Dzingute A, Masiliunaite V, Sulcaite G, Zilinskas J. PEEK polymer's properties and its use in prosthodontics. A review. Stomatologija. 2018 Jan 1;20(2):54-8.

[22]. Qin L, Yao S, Zhao J, Zhou C, Oates TW, Weir MD, et al. Review on Development and Dental Applications of Polyetheretherketone-Based Biomaterials and Restorations. Materials (Basel). 2021 Jan 15;14(2):408.Pubmed PMID: 33467576

[23]. Najeeb S, Zafar MS, Khurshid Z, Siddiqui F. Applications of polyethere- therketone (PEEK) in oral implantology and prosthodontics. J PROSTHODONT RES. 2016 Jan 1;60(1):12-9.

[24]. Rahmitasari F, Ishida Y, Kurahashi K, Matsuda T, Watanabe M, Ichikawa T. PEEK with Reinforced Materials and Modifications for Dental Implant Applications. Dent J (Basel). 2017 Dec 15;5(4):35.Pubmed PMID: 29563441.

[25]. Schwitalla A, Müller WD. PEEK dental implants: a review of the literature. J Oral Implantol. 2013 Dec;39(6):743-9.

26]. Zoidis P, Bakiri E, Papathanasiou I, Zappi A. Modified PEEK as an alternative crown framework material for weak abutment teeth: a case report. Gen Dent. 2017 Sep-Oct;65(5):37-40.Pubmed PMID: 28862587.

[27]. Nazari V, Ghodsi S, Alikhasi M, Sahebi M, Shamshiri AR. Fracture Strength of Three-Unit Implant Supported Fixed Partial Dentures with Excessive Crown Height Fabricated from Different Materials. J Dent (Tehran). 2016 Nov;13(6):400-406.Pubmed PMID: 28243301.

[28]. Zoidis P, Papathanasiou I, Polyzois G. The Use of a Modified Poly-EtherEther-Ketone (PEEK) as an Alternative Framework Material for Removable Dental Prostheses. A Clinical Report. J Prosthodont. 2016 Oct;25(7):580584.Pubmed PMID: 26216668.

[29]. Whitty T. PEEK-A New Material for CAD/CAM Dentistry. Juvora Dental Innovations. 2014:32-35.

[30]. Stawarczyk B, Beuer F, Wimmer T, Jahn D, Sener B, Roos M, et al. Polyetheretherketone-a suitable material for fixed dental prostheses?. J. Biomed. Mater. Res. - Part B Appl. Biomater. 2013 Oct;101(7):1209-16.

[31]. Stawarczyk B, Jordan P, Schmidlin PR, Roos M, Eichberger M, Gernet W, et al. PEEK surface treatment effects on tensile bond strength to veneering resins. J Prosthet Dent. 2014 Nov 1;112(5):1278-88.

[32]. Stawarczyk B, Keul C, Beuer F, Roos M, Schmidlin PR. Tensile bond strength of veneering resins to PEEK: impact of different adhesives. Dent. Mater. J. 2013 May 30;32(3):441-8.

[33]. Hallmann L, Mehl A, Sereno N, Hämmerle CH. The improvement of adhesive properties of PEEK through different pre-treatments. Appl. Surf. Sci. 2012 Jul 1;258(18):7213-8.

[34]. Biacchi GR, Mello B, Basting RT. The endocrown: an alternative approach for restoring extensively damaged molars. J Esthet Restor Dent. 2013 Dec;25(6):383-90.

[35]. Carlos RB, Thomas Nainan M, Pradhan S, Roshni Sharma, Benjamin S, Rose R. Restoration of endodontically treated molars using all ceramic endocrowns. Case Rep Dent. 2013;2013:1-5.Pubmed PMID: 24455318.

[36]. Saglam G, Cengiz S, Karacaer O. Marginal adaptation and fracture resistance of feldspathic and polymer-infiltrated ceramic network CAD/CAM endocrowns for maxillary premolars. Niger J Clin Pract. 2020 Jan;23(1):1-6. Pubmed PMID: 31929199.

[37]. A. A. Turkistani, M. Dimashkieh, and M. Rayyan. Fracture resistance of teeth restored with endocrowns: An in vitro study. J. Esthet. Restor. Dent. 2019.

[38]. El Ghoul W, Özcan M, Silwadi M, Salameh Z. Fracture resistance and failure modes of endocrowns manufactured with different CAD/CAM materials under axial and lateral loading. J Esthet Restor Dent. 2019 Jul;31(4):378 387.Pubmed PMID: 31067007.

[39]. Altier M, Erol F, Yıldırım G, Dalkilic EE. Fracture resistance and failure modes of lithium disilicate or composite endocrowns. Niger. J. Clin. Pract. 2018 Jul 16;21(7):821-6.

[40]. Skalskyi V, Makeev V, Stankevych O, Pavlychko R. Features of fracture of prosthetic tooth-endocrown constructions by means of acoustic emission analysis. Dent Mater. 2018 Mar;34(3):e46-e55.Pubmed PMID: 29409675.

[41]. Dartora NR, de Conto Ferreira MB, Moris ICM, Brazão EH, Spazin AO, Sousa-Neto MD, et al. Effect of Intracoronal Depth of Teeth Restored with Endocrowns on Fracture Resistance: In Vitro and 3-dimensional Finite Element Analysis. J Endod. 2018 Jul;44(7):1179-1185.Pubmed PMID: 29866407.

[42]. Zoidis P, Bakiri E, Polyzois G. Using modified polyetheretherketone (PEEK) as an alternative material for endocrown restorations: A short-term clinical report. J Prosthet Dent. 2017 Mar;117(3):335-339.Pubmed PMID: 27692583.

[43]. Ghajghouj O, Taşar-Faruk S. Evaluation of Fracture Resistance and Microleakage of Endocrowns with Different Intracoronal Depths and Restorative Materials Luted with Various Resin Cements. Materials (Basel). 2019 Aug 8;12(16):2528.Pubmed PMID: 31398883.

[44]. Elashmawy Y, Elshahawy W, Seddik M, Aboushelib M. Influence of fatigue loading on fracture resistance of endodontically treated teeth restored with endocrowns. J PROSTHODONT RES. 2021:JPOR 2019485.

[45]. Veselinović V, Todorović A, Lisjak D, Lazić V. Restoring endodontically treated teeth with all-ceramic endo-crowns: case report. Stomatol. Glas. Srb. 2008;55(1):54-64

[46]. Gresnigt MM, Özcan M, van den Houten ML, Schipper L, Cune MS. Fracture strength, failure type and Weibull characteristics of lithium disilicate and multiphase resin composite endocrowns under axial and lateral forces. 
Dent Mater. 2016 May;32(5):607-14.Pubmed PMID: 26935018.

[47]. El-Damanhoury HM, Haj-Ali RN, Platt JA. Fracture resistance and microleakage of endocrowns utilizing three CAD-CAM blocks. Oper Dent. 2015 Mar-Apr;40(2):201-10.Pubmed PMID: 25268039.

[48]. Hayes A, Duvall N, Wajdowicz M, Roberts H. Effect of endocrown pulp chamber extension depth on molar fracture resistance. Oper. Dent. 2017;42(3):327-34.

[49]. R. Patrick, M. Roos, and M. Eichberger. PEEK surface treatment effects on tensile bond strength to veneering resins PEEK surface treatment effects on tensile bond strength to veneering resins Short title : Bonding properties between PEEK and resin composite Bogna Stawarczyk, Dr . rer . biol.2014;112.

[50]. Stawarczyk B, Bähr N, Beuer F, Wimmer T, Eichberger M, Gernet W, et al. Influence of plasma pretreatment on shear bond strength of self-adhesive resin cements to polyetheretherketone. Clin Oral Investig. 2014 Jan;18(1):16370.Pubmed PMID: 23504226.

[51]. Varga S, Spalj S, Lapter Varga M, Anic Milosevic S, Mestrovic S, Slaj M. Maximum voluntary molar bite force in subjects with normal occlusion. Eur. J. Orthod. 2011 Aug 1;33(4):427-33.

[52]. Della Bona A, Mecholsky Jr JJ, Anusavice KJ. Fracture behavior of lithia disilicate-and leucite-based ceramics. Dent Mater. 2004 Dec 1;20(10):956-62.

[53]. Taha D, Spintzyk S, Sabet A, Wahsh M, Salah T. Assessment of marginal adaptation and fracture resistance of endocrown restorations utilizing different machinable blocks subjected to thermomechanical aging. J Esthet Restor Dent. 2018 Jul;30(4):319-328.Pubmed PMID: 30113129.

[54]. Zheng Z, He Y, Ruan W, Ling Z, Zheng C, Gai Y, et al. Biomechanical behavior of endocrown restorations with different CAD-CAM materials: A 3D finite element and in vitro analysis. J Prosthet Dent. 2020 Jun;125(6):890899.Pubmed PMID: 32471627.

[55]. Nguyen JF, Migonney V, Ruse ND, Sadoun M. Resin composite blocks via high-pressure high-temperature polymerization. Dent Mater . 2012 May $1 ; 28(5): 529-34$.

[56]. Lauvahutanon S, Takahashi H, Shiozawa M, Iwasaki N, Asakawa Y, Oki M, et al. Mechanical properties of composite resin blocks for CAD/CAM. Dent. Mater. J. 2014 Sep 30;33(5):705-10.

[57]. Magne P, Schlichting LH, Maia HP, Baratieri LN. In vitro fatigue resistance of CAD/CAM composite resin and ceramic posterior occlusal veneers. J Prosthet Dent. 2010 Sep;104(3):149-57. doi: 10.1016/S0022-3913(10)601114. PMID: 20813228.

[58]. Rees JS, Jagger DC. Abfraction lesions: myth or reality?. J Esthet Restor Dent. 2003 Sep;15(5):263-71.

[59]. Bathala L, Majeti V, Rachuri N, Singh N, Gedela S. The Role of Polyether Ether Ketone (Peek) in Dentistry - A Review. J Med Life. 2019 JanMar;12(1):5-9.Pubmed PMID: 31123518.

[60]. Soares CJ, Pizi EC, Fonseca RB, Martins LR. Influence of root embedment material and periodontal ligament simulation on fracture resistance tests. Braz. Oral Res. 2005;19(1):11-6. 